\title{
Settlement and Recruitment Potential of Four Invasive and One Indigenous Barnacles in South Korea and Their Future
}

\author{
Michael Dadole Ubagan ${ }^{1,2,+}$, Yun-Sik Lee ${ }^{1,3,+} \mathbb{C}$, Taekjun Lee ${ }^{1} \mathbb{C}$, Jinsol Hong ${ }^{4} \mathbb{\oplus}$, Il Hoi Kim ${ }^{1}$ \\ and Sook Shin $1,3, *,+$ \\ 1 Marine Biological Resources Institute, Sahmyook University, Seoul 01795, Korea; \\ summer_09.breeze@yahoo.com (M.D.U.); ssamppong@korea.ac.kr (Y.-S.L.); dagock@hanmail.net (T.L.); \\ ihkim@gwnu.ac.kr (I.H.K.) \\ 2 Department of Animal Biotechnology and Resource, College of Science and Technology, \\ Sahmyook University, Seoul 01795, Korea \\ 3 O-Jeong Resilience Institute, Korea University, Seoul 02841, Korea \\ 4 Division of Environmental Science and Ecological Engineering, Korea University, Seoul 02841, Korea; \\ jinso19005@korea.ac.kr \\ * Correspondence: shins@syu.ac.kr; Tel.: +85-02-3399-1717; Fax: +85-02-3399-1762 \\ + These authors contributed equally to this work.
}

Citation: Ubagan, M.D.; Lee, Y.-S.; Lee, T.; Hong, J.; Kim, I.H.; Shin, S. Settlement and Recruitment Potential of Four Invasive and One Indigenous Barnacles in South Korea and Their Future. Sustainability 2021, 13, 634. https://doi.org/10.3390/su13020634

Received: 17 November 2020 Accepted: 7 January 2021

Published: 11 January 2021

Publisher's Note: MDPI stays neutral with regard to jurisdictional clai$\mathrm{ms}$ in published maps and institutional affiliations.

Copyright: (C) 2021 by the authors. Licensee MDPI, Basel, Switzerland. This article is an open access article distributed under the terms and conditions of the Creative Commons Attribution (CC BY) license (https:// creativecommons.org/licenses/by/ $4.0 /)$.

\begin{abstract}
Invasion by nonindigenous species is a major threat to marine ecosystems. In this study, the distribution and occupied area (as a percentage) of four invasive barnacles (Amphibalanus amphitrite, Amphibalanus eburneus, Amphibalanus improvisus, Perforatus perforatus), and one indigenous (Balanus trigonus) barnacle in 13 ports in three Korean seas (East sea, Korea Strait, and Yellow Sea) were investigated. The average ratio for all five species was $11.17 \%$ in summer and $7.59 \%$ in winter, indicating a higher occupancy in summer. B. trigonus, which is an indigenous species, was found on all ports, except for one (IC). Of the invasive species, A. amphitrite was found mainly in the Yellow Sea, A. improvisus in the Korea Strait, and A. eburneus along with P. perforatus were found in the East Sea. From nonmetric multidimensional scaling (NMDS) analysis, six parameters related to water temperature and salinity were found to be significantly correlated with the distribution and occupancy status of these five barnacles. Using the six parameters as independent variables, random forest (RF) models were developed. Based on these models, the predicted future dominant invasive species were A. improvisus and A. amphitrite in the Yellow Sea and P. perforatus in the East Sea and Korea Strait. This study suggests that long-term monitoring of invasive species is crucial, and that determining the relationship between the results of monitoring and environmental variables can be helpful in predicting the damage caused by invasive species resulting from environmental changes.
\end{abstract}

Keywords: Barnacles; distribution; environmental factors; invasive species; seasons

\section{Introduction}

Barnacles are sessile, filter-feeding crustaceans that attach to a variety of marine substrata [1], making space for attachment and facilitating feeding and reproduction [2]. Hence, barnacles are found attached to rocks, wharf pilings, mollusk shells, crustacean exoskeletons, and other hard surfaces [3]. They are well-known ship-fouling organisms, and thus many species have been translocated to new regions of the world through human activities, such as the international shipping trade [4]. If invasive species succeed in the colonization of the new region, they affect the ecology of indigenous species. In many studies, invasive species have been found to coexist with indigenous species $[5,6]$; however, these invasive species can reduce the biodiversity or abundance of indigenous species when the environment is modified to provide favorable conditions for invasive species $[7,8]$. One such environmental change is water temperature and salinity shifts due to climate change. For example, the invasive barnacles in Europe, Austrominius modestus, has been present at 
low density since the 1940s, but now, the number of $A$. modestus has been recorded as more than that of the indigenous barnacle at some locations, including the Irish marine nature reserve [9]. For this reason, the biology of invasive barnacles and their establishment in new regions has become the focal point of research regarding the protection of indigenous barnacles under climate change.

Successful colonization of invasive barnacles depends primarily on water temperature and salinity $[10,11]$. Since colonization is the most important step in their life cycle, the effects of water temperature and salinity on settlement and establishment rates have been investigated in laboratory experiments [11,12]. However, few studies have investigated the relationship between the distribution and occupancy status of barnacles and environmental variables in the field. As the inflow of invasive barnacles is concentrated mainly in ports, such as international shipping traffic ports [13], it is necessary to investigate their settlement and establishment potential by analyzing the composition of barnacle communities in major ports, along with water temperature and salinity.

Distribution and dissemination of invasive barnacles in Korean coastal waters are usually influenced by ships, and several invasive barnacles have already spread to all Korean coasts (East sea, Korea Strait, and Yellow Sea) [14]. The first reported points of entry for invasive barnacles in the Korean seas were in parts of the Korea Strait and the East Sea [15-17]. Consequently, continuous monitoring of species has been performed in major ports in Korea [18]. Based on this monitoring, four invasive barnacles (Amphibalanus amphitrite, Amphibalanus eburneus, Amphibalanus improvisus, and Perforatus perforatus) were selected as candidates for analysis of ecological disturbance because they were dominant in several ports [18]. In addition, Balanus trigonus, a known indigenous barnacle found nationwide, was also chosen for comparative study [19].

The objectives of this study were: (1) to investigate the distribution and occupancy status of four invasive and one indigenous barnacle; (2) to evaluate the relationship between the status of the five barnacles and environmental variables related to water temperature and salinity; and (3) to predict future dominant species. The relationship between predicted water temperature and salinity and the composition of the present community of barnacles are briefly discussed. Based on this relationship, the possibility of invasive species dominance under climate change was predicted and discussed. This is the first study to investigate and predict the relationship between invasive and indigenous barnacles on a regional scale in Korea.

\section{Materials and Methods}

\subsection{Study Area and Sampling Sites}

Korea, the area of interest in the present study, is located in a temperate zone with four distinct seasons. The Korean peninsula is surrounded on three sides by seas, and there are three sea areas (Yellow Sea, Korea Strait, and East Sea) based on the coastal area (Figure 1). In total, 13 harbors or ports that had a high potential influx of barnacles were selected as sampling sites. Five sampling sites (SC, DH, JB, YP, and US) in the East Sea were selected; four (BS, TY, KY, YS) in the Korea Strait; and four (MP, BE, DJ, IC) in the Yellow Sea (Figure 1, Table S1). The locations of the sampling sites are shown in Figure 1 and their GPS coordinates are listed in Table S1. 


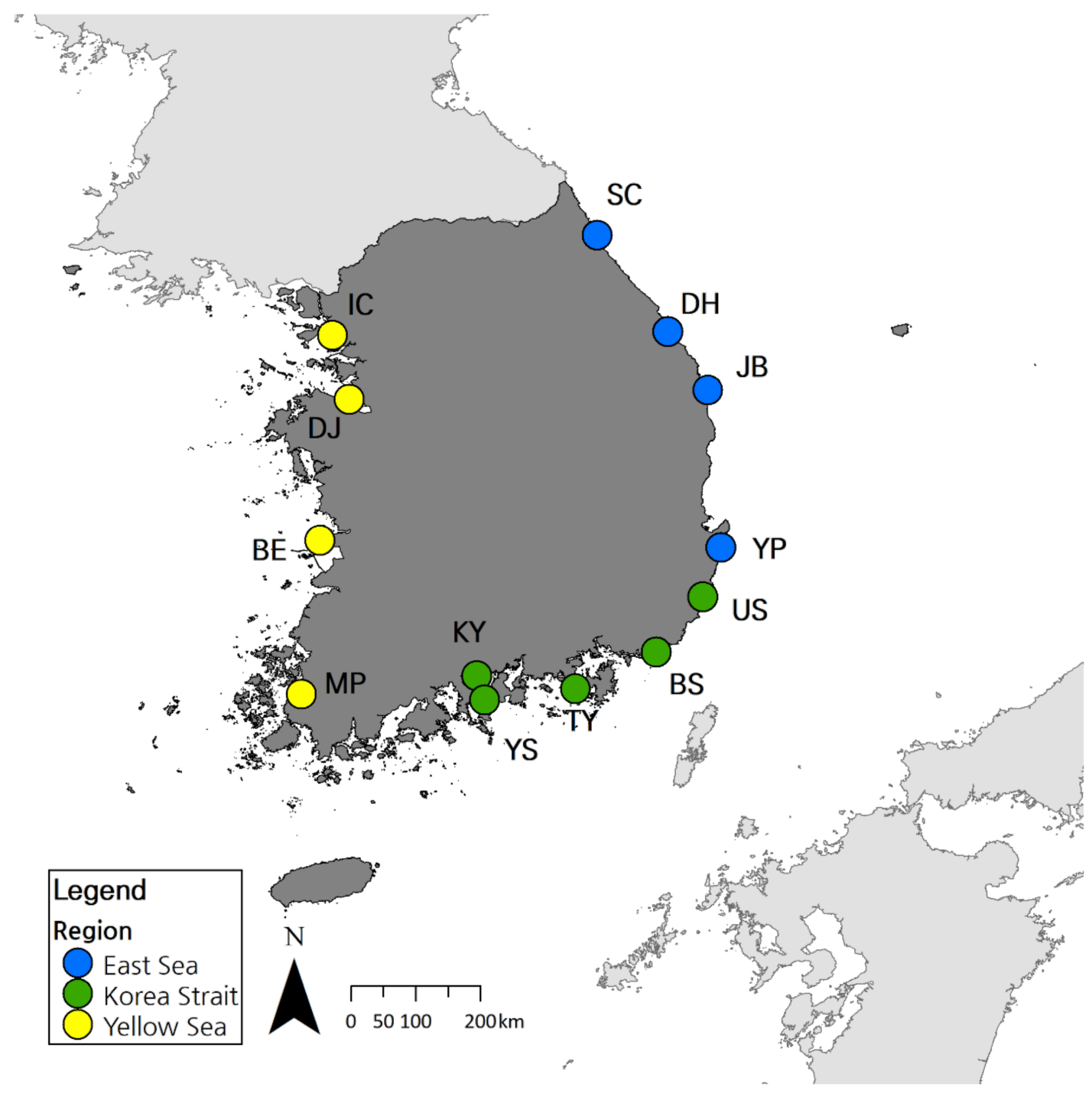

Figure 1. A map showing the 13 sampling sites surveyed in East Sea, Korea Strait, and Yellow Sea. Information on each sampling site is presented in Table S1.

\subsection{Test Barnacles}

Four invasive and one indigenous species were selected for this study (Table 1). A. amphitrite (Darwin, 1854) (AMP), A. eburneus (Gould, 1841) (EBU), A. improvisus (Darwin, 1854) (IMP), and P. perforatus (Bruguière, 1789) (PER) have been known as invasive barnacles because they may cause disturbances in the marine ecosystems of Korea [18]. Balanus trigonus Darwin, 1854 (TRI), was selected because it is the most prevalent barnacle in Korea [19] and is a type of indigenous species that may be disturbed by invasive species. 
Table 1. Scientific name, abbreviation, origin, year of invasion, and reference for the examined species in the present study.

\begin{tabular}{|c|c|c|c|c|}
\hline Species & Abbr. & Origin & Year of Invasion & Reference \\
\hline Amphibalanus amphitrite & AMP & Unknown & 1979 & [15] \\
\hline Amphibalanus eburneus & EBU & North Atlantic Ocean & - & [16] \\
\hline Amphibalanus improvisus & IMP & Easern North America & $1990 \mathrm{~s}$ & {$[16]$} \\
\hline Perforatus perforatus & PER & $\begin{array}{c}\text { Western Europe, Northwest coast of Africa, } \\
\text { Mediterranean Sea }\end{array}$ & 2000 & [17] \\
\hline Balanus trigonus & TRI & Native species & & \\
\hline
\end{tabular}

\subsection{Sampling Design and Calculation of Barnacle Occupied Area}

At each sampling site, 10 acrylic attachment plates $(30 \mathrm{~cm} \times 30 \mathrm{~cm})$ to which barnacles could attach and inhabit were installed at a depth of between 1 and $3 \mathrm{~m}$ from the sea level at low tide. The attachment plates were submerged and exposed for 6 months each in the warm season and the cold season. The warm season was from May to October 2017, comprising mainly spring and summer, and the cold season was from November 2017 to April 2018, comprising autumn and winter.

During the six-month installation in each sampling season, various sessile organisms, including barnacles, fastened to the surface of the attachment plates. The attachment plates were removed from the water and placed on a flat surface. Then, the surface of the attachment plates was photographed using a vertically fixed digital camera (Olympus TG-5). The occupied area of each test species and the total area of the attachment plate were calculated based on an analysis of the pixels using ImageJ software [20]. The barnacle occupancy area (\%) was calculated as the ratio of the occupied area of the target species to the total area of the attachment plate. This method has been used for a long time to measure the recruitment potential and abundance of sessile marine organisms [21-23]. In this study, the barnacle occupancy area was considered as the fitness of the barnacles in each sampling area.

\subsection{Environmental Variables}

To extrapolate the temperature and salinity data of each sampling site, the default inverse distance weighting method (IDW) function in the R 'gstat' package was used [24]. The surface temperature and salinity data of 28 ports in Korea measured by the marine environment monitoring network were used for IDW (Table S2) [25]. The average monthly water temperature and salinity were extrapolated from May 2017 to April 2018 at each sampling site. In this study, the average min and max values of the warm and cold seasons (AT, ATmax, and ATmin for water temperature; S, Smax, and Smin for salinity, respectively) were calculated based on predicted water temperature and salinity.

\subsection{Statistical Analysis}

For each sampling season, the barnacle occupancy area of five test species derived from 130 attachment plates was used for the analysis of nonmetric multi-dimensional scaling (NMDS). To evaluate the relationships between distribution and abundance of barnacle, environmental factors, and sea areas, NMDS was performed on the dataset of the barnacle occupancy area of the five test species, based on two axes and the Bray-Curtis distance with 9999 iterations. To identify the differences in the sea area, the associated confidence ellipses $(\alpha=0.05)$ were superimposed on the NMDS biplot and permutation multivariate analyses of variance (PERMANOVAs) were used to test the significance of differences among the composition of each barnacle in each sea area. In addition, environmental factors were tested for a significant correlation with NMDS, and factors were identified at a significance level of $5 \%$. This analysis was conducted using the $R$ 'vegan' package. 
Random forest (RF) methodology [26] was used to estimate the dominant species at present and in the future at each sampling site. RF is a machine learning method based on a decision tree. This method takes the average of a large number of trees (forest) and builds through randomly finding and splitting feature nodes (random). This method is popular because of its easy applicability to classification and regression problems with complex interactions [27]. The dominant species among the five test species on 130 attachment plates in each sampling season were used to develop a random forest (RF) classifier. Of the 130 results, $70 \%$ comprised the training set, and 30\% comprised the testing set. The analysis was designed to predict which barnacle dominated according to the significant environmental factors selected in the NMDS analysis. To run the RF classifier, the $m$ try and ntree parameters were set. The terms mtry and ntree refer to the number of input variables used at each node and the number of classification trees, respectively. The optimum values of ntree and mtry were selected based on the lowest out-of-bag error and the highest accuracy (Table S3). The-out-of-bag (OOB) error of the RF classifier was measured by cross-validation using OOB samples, and the accuracy was calculated as the ratio of the number of results accurately predicting the observed dominant species in the total number of testing sets. However, accuracy was affected by mtry but not by ntree. Therefore, the combination of ntree and mtry with the lowest OOB error was selected. The mean decrease in accuracy (MDA) criterion was used to evaluate the importance of environmental factors used as input data. After the complete development of the RF classifier, the dominant species at each sampling site was predicted and changes in the dominant species after 30 , 50, and 100 years were predicted by considering simple climate change. Simple climate change was considered to represent an average increase in the warming rate of the surface water temperature by $0.11{ }^{\circ} \mathrm{C}$ per year [28] and a decrease in salinity of 0.015 PSU per 10 years [29]. All analyses related to the RF classifier were conducted using the R 'random forest' package [30].

\section{Results}

\subsection{Water Temperature and Salinity}

Overall, the monthly average water temperature at all sampling sites followed a similar pattern; most sampling sites had the highest temperature in August and the lowest temperature in February (Figure 2). The values ranged from $13.2{ }^{\circ} \mathrm{C}$ to $28.7^{\circ} \mathrm{C}$ during the warm season and from $0.1{ }^{\circ} \mathrm{C}$ to $17.1^{\circ} \mathrm{C}$ during the cold season. The average water temperature for 6 months ranged from $19.7^{\circ} \mathrm{C}$ in the East Sea to $21.8^{\circ} \mathrm{C}$ in the Yellow Sea during the warm season and from $7.48^{\circ} \mathrm{C}$ in the Yellow Sea to $11.22{ }^{\circ} \mathrm{C}$ in the Korea Strait in the cold season. The difference in water temperature between the warm and cold seasons was largest in the Yellow Sea $\left(14.3^{\circ} \mathrm{C}\right)$ and the smallest in the East Sea $\left(8.5^{\circ} \mathrm{C}\right)$. Consequently, in the warm season, the East Sea had the lowest water temperature, and in the cold season, the Yellow Sea had the lowest water temperature. In the Korea Strait, the water temperature was relatively warm throughout the year. The salinity of the water during the warm season ranged from 27.3 to $34.2 \mathrm{psu}$, and from 27.1 to $35.6 \mathrm{psu}$ during the cold season. From July to September, low salinity was found at all sampling sites because of heavy rain during the summer monsoon season. Unlike the pattern of monthly water temperature, the Yellow Sea had the lowest salinity, regardless of the season. 

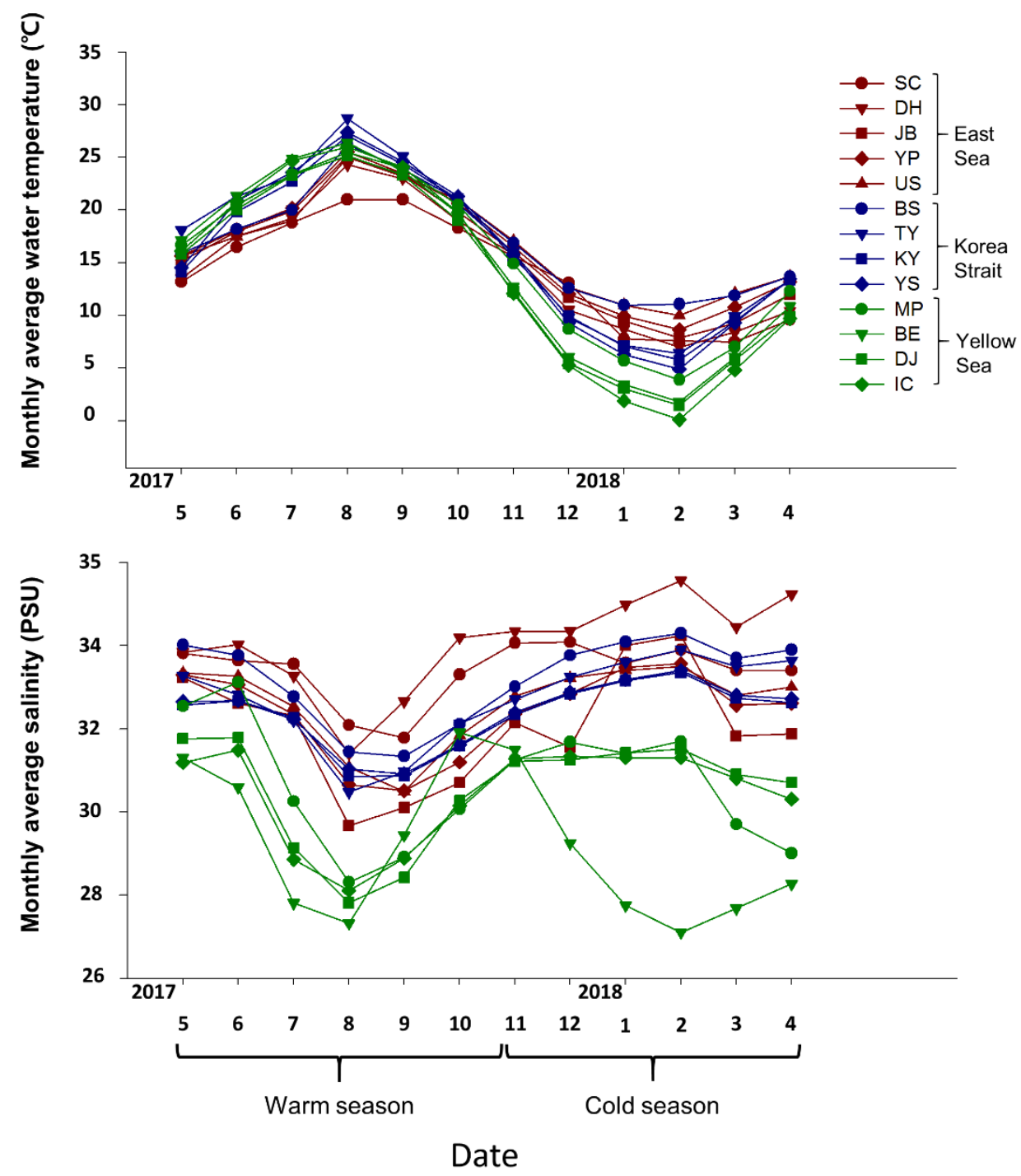

Figure 2. Monthly average water temperature and average salinity at each sampling site from May 2017 to April 2018. These data were extrapolated using the distance weighting method (IDW) function. The sampling sites were divided into three categories (East Sea, Korea Strait, Yellow Sea) based on their location and the sampling dates were divided into two categories (warm season and cold season).

\subsection{Distribution and Occupied Area of the Barnacles}

A. amphitrite was found mainly in the Yellow Sea, A. improvisus in the Korea Strait, and A. eburneus and P. perforatus in the East Sea. The average of the sum of the occupied area of the five species was $11.17 \%$ in the warm season and $7.59 \%$ in the cold season; in most cases, the occupied area was greater in summer. The occupied area of each species, based on the sampling site and season, was calculated to identify their density (Figure 3). The occupied area of AMP ranged from $0.5 \%$ at DJ to $10.8 \%$ at IC in the warm season, and from $0.3 \%$ at $\mathrm{BE}$ to $8.4 \%$ at IC in the cold season. AMP was distributed predominantly in the Yellow Sea and appeared seasonally in the Korea Strait (KY in the warm season) and the East Sea (DH and US in the cold season) with a smaller occupied area. The occupied area of PER ranged from $0.1 \%$ at KY to $4.8 \%$ at SC during the warm season, and from $0.2 \%$ at BS to $2.4 \%$ at US during the cold season. PER was distributed predominantly in the East Sea regardless of the season, and in the warm season, it appeared in the low occupancy areas in the Korea Strait and parts of the Yellow Sea (MP). In the case of EBU, relatively low occupancy areas were observed compared with the other species. The largest occupancy of EBU was $1.4 \%$ at DH in the warm season. In the warm season, EBU appeared in the East 
Sea and the Korea Strait, but in the cold season, only appeared at SC. IMP was the most abundant invasive barnacle. The occupied area of IMP ranged from $0.1 \%$ at $\mathrm{DH}$ and JB to $10.8 \%$ at TY during the warm season, and from $0.05 \%$ at DH and JB to $43.4 \%$ at $\mathrm{KY}$ during the cold season. IMP was distributed predominantly in the Korea Strait and the Yellow Sea, and was observed at all of the sampling sites except BS. TRI, the native species in Korea, appeared at all sampling sites except IC, and more occupied areas were observed during the warm season than during the cold season. The occupied area of TRI varied from $0.3 \%$ at BE to $38.4 \%$ at BS during the warm season, and from $0.4 \%$ at DH to $10.3 \%$ at $Y S$ during the cold season.

(a)

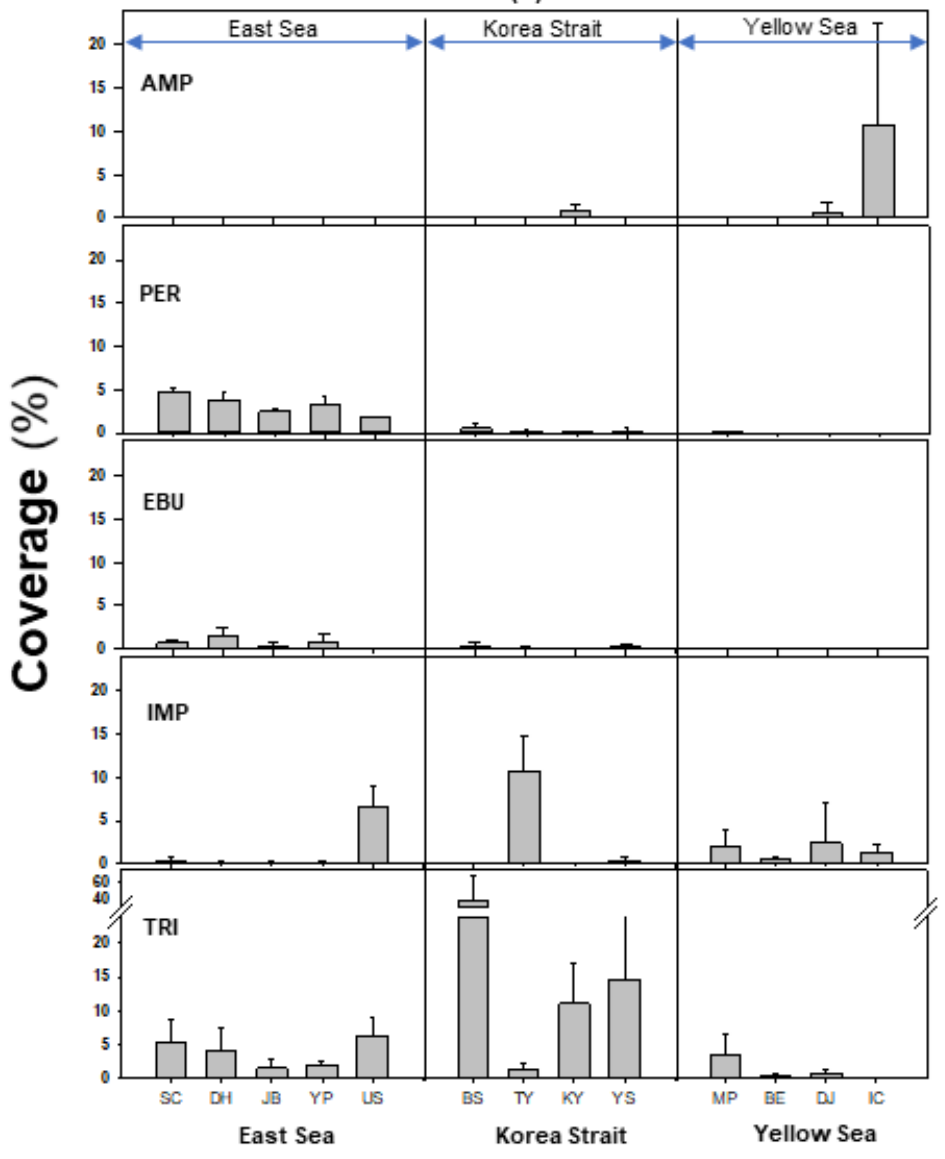

(b)

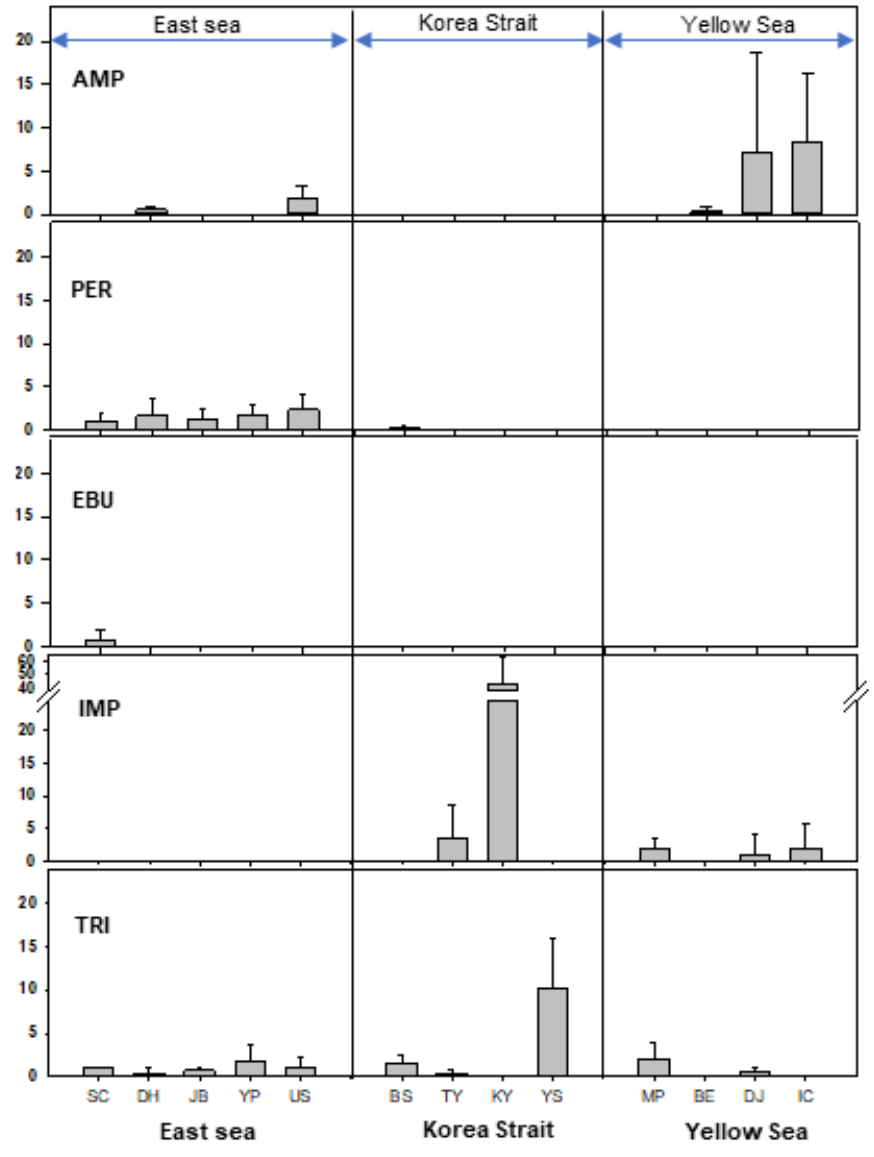

\section{Sampling site}

Figure 3. Mean occupied area of five barnacles at 13 sampling sites in Korea (East Sea, Korea Strait, Yellow Sea) during the warm season (a) and the cold season (b). The error bars represent the standard deviations. The abbreviations of the sampling site and barnacles are defined in Table 1 and Table S1.

\subsection{NMDS Analysis}

The NMDS analysis showed that the barnacles were dispersed widely across the 2-dimensional space according to their distribution and occupied areas (Figure 4). In this analysis, it is found that the composition of the five barnacles is different according to the sea area, and water temperature and salinity were significant involved. The results of NMDS were a good reflection of the sampling data (stress $=0.10 ; R^{2}=0.989$ for nonmetric fit in the warm season; stress $=0.07 ; \mathrm{R}^{2}=0.994$ for nonmetric fit in the warm season). The component of the occupied areas differed significantly among the sea area in NMDS space during both the warm and cold seasons (PERMANOVA; $\mathrm{F}=26.6 ; \mathrm{df}=2,125$; $p<0.0001$ during the warm season; $\mathrm{F}=18.8 ; \mathrm{df}=2,121 ; p<0.0001$ during the warm season). 
Confidence ellipses overlapped in all the sea areas, but in the results of the PERMANOVA pairwise comparisons among sea areas, the composition of occupied areas in the East Sea was significantly different from the other sea areas (Korea Strait and Yellow Sea) $(p<0.0001$, Table 2). Meanwhile, the composition of the occupied areas was significantly related to the average water temperature (AT), maximum monthly water temperature ( $\left.\mathrm{AT}_{\max }\right)$, minimum monthly water temperature ( $\left.\mathrm{AT}_{\min }\right)$, average salinity $(\mathrm{S})$, maximum monthly salinity $\left(\mathrm{S}_{\max }\right)$, and minimum monthly salinity $\left(\mathrm{S}_{\mathrm{min}}\right)$ during both the warm and cold seasons (Table 3$)$. These results indicated that the environmental variables related to water temperature and salinity significantly affected the distribution and occupied areas. In the case of $\mathrm{AT}_{\max }, \mathrm{AT}$, and $\mathrm{AT}_{\min }$, the fitted vectors (arrows) pointed toward the Yellow Sea group in the warm season, but in the cold season, these vectors pointed in the opposite direction to the Yellow Sea group, because of the large temperature difference between seasons. This was because the difference in average water temperature between the warm and cold seasons was the largest in the Yellow Sea and the smallest in the East Sea.
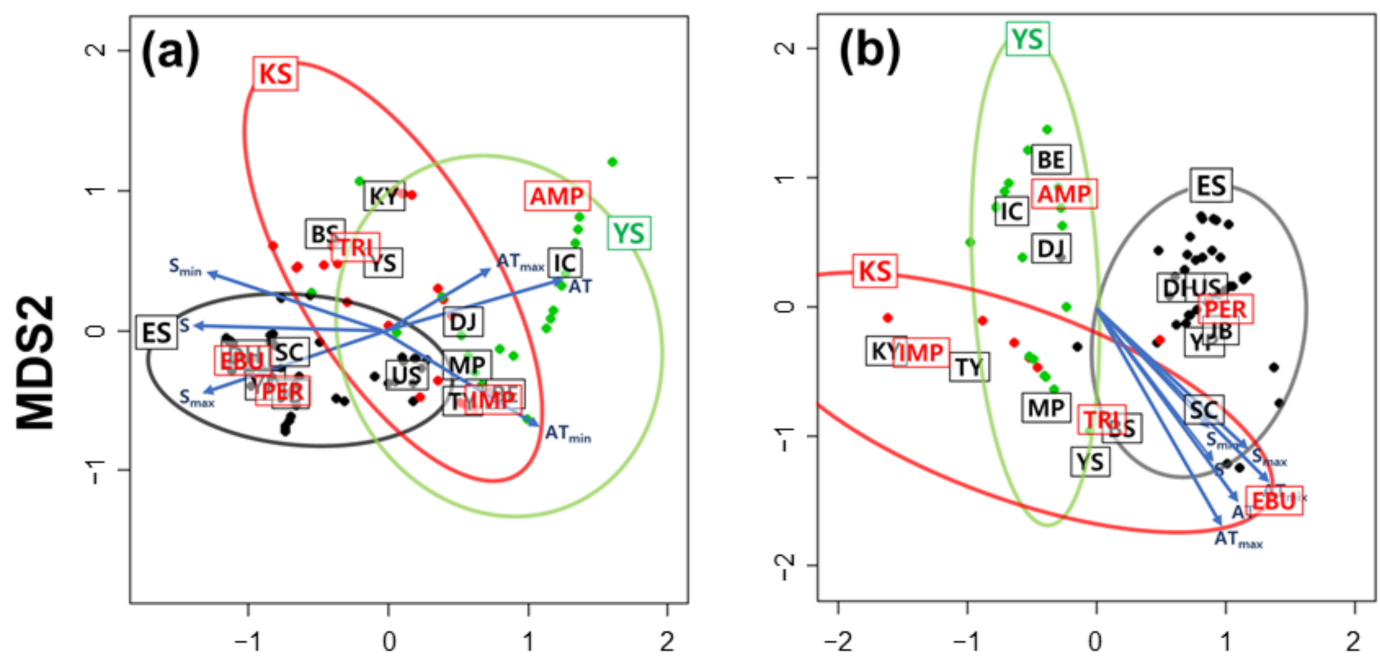

\section{MDS1}

Figure 4. NMDS analysis based on the occupied area of barnacles on the settlement plate during the warm season (a) and cold season (b) with the superimposition of the confidence ellipses (for $\alpha=0.05$ ), relative to the East Sea (ES; Black), the Korea Strait (KS; Red), and the Yellow Sea (YS; green). The text in the black and red boxes indicates the sampling site and barnacles, respectively. The arrows represent the significant variables related to water temperature and salinity as determined by the function "envfit" ( $p<0.05$, Table 3$)$. The abbreviations of sampling site and barnacles are detailed in Table 1 and Table S1.

Table 2. The permuted $p$-value of PERMANOVA pairwise comparisons of the composition of five barnacles (AMP, PER, EBU, IMP, TRI) between three Korean sea areas (Yellow Sea, Korea Strait, East Sea). $p$-values are based on 9999 permutations: $p<0.05\left(^{*}\right)$.

\begin{tabular}{ccc}
\hline Sampling Site & Warm Season & Cold Season \\
\hline East Sea vs. Korea Strait & $<0.0001^{*}$ & $<0.0001^{*}$ \\
East Sea vs. Yellow Sea & $<0.0001^{*}$ & $<0.0001^{*}$ \\
Korea Strait vs. Yellow Sea & 0.4966 & 0.1660 \\
\hline
\end{tabular}


Table 3. The square of the correlation coefficient $\left(\mathrm{R}^{2}\right)$ and $P$-values of variables calculated explaining the composition of five barnacles. $p$-values are based on 9999 permutations: $0<p<0.001\left(^{*}\right)$.

\begin{tabular}{|c|c|c|c|c|}
\hline \multirow[b]{2}{*}{ Variables } & \multicolumn{2}{|c|}{ Warm Season } & \multicolumn{2}{|c|}{ Cold Season } \\
\hline & $\mathbf{R}^{2}$ & $p$-Value & $\mathbf{R}^{2}$ & $p$-Value \\
\hline Average water temperature (AT) & 0.4956 & $<0.0001 *$ & 0.4016 & $<0.0001 *$ \\
\hline Maximum monthly water temperature $\left(\mathrm{AT}_{\max }\right)$ & 0.2040 & $<0.0001 *$ & 0.4517 & $<0.0001$ * \\
\hline Minimum monthly water temperature $\left(\mathrm{AT}_{\min }\right)$ & 0.4858 & $<0.0001 *$ & 0.4326 & $<0.0001$ * \\
\hline Average salinity (S) & 0.5553 & $<0.0001 *$ & 0.2608 & $<0.0001 *$ \\
\hline Maximum monthly salinity $\left(S_{\max }\right)$ & 0.5795 & $<0.0001 *$ & 0.3049 & $<0.0001$ * \\
\hline Minimum monthly salinity $\left(\mathrm{S}_{\min }\right)$ & 0.5181 & $<0.0001^{*}$ & 0.1958 & $<0.0001$ * \\
\hline
\end{tabular}

\subsection{Estimation of Dominant Barnacle Using a Random Forest Model}

According to the results of the NMDS analysis, six environmental variables (shown in Table 3) were significant factors affecting the distribution and coverage of barnacles. Thus, these factors were employed as independent variables for the prediction of the dominant barnacle in the random forest model. Separate random forest classifiers were created for the warm and cold seasons. The final optimized conditions were selected based on out-ofbag estimates of error rate and prediction accuracy between the observed and predicted dominant species of the test set (Table S3). The conditions of $n$ tree $=10$ and mtry $=4$ were used by applying the two random forest models for the classification of dominant barnacle at each sampling site. The prediction accuracy of the random forest model was $74.3 \%$ in the warm season and $83.3 \%$ in the cold season (Table S2).

Based on the mean decreased accuracy, the variable importance was measured for six environmental variables (Figure 5). This result indicated that the importance of environmental variables that determined the dominant species differed between the warm and cold seasons. The mean decreased accuracy criterion delivered as an output of the random forest model for the warm season showed that $S_{\min }$ (4.59) was the most important variable for the prediction of dominant barnacle. In addition, $\mathrm{AT}_{\min }$ (4.39) was also a notably important variable. For the cold season, $\mathrm{AT}_{\min }$ (7.89) was the most important variable compared with the other environmental factors.
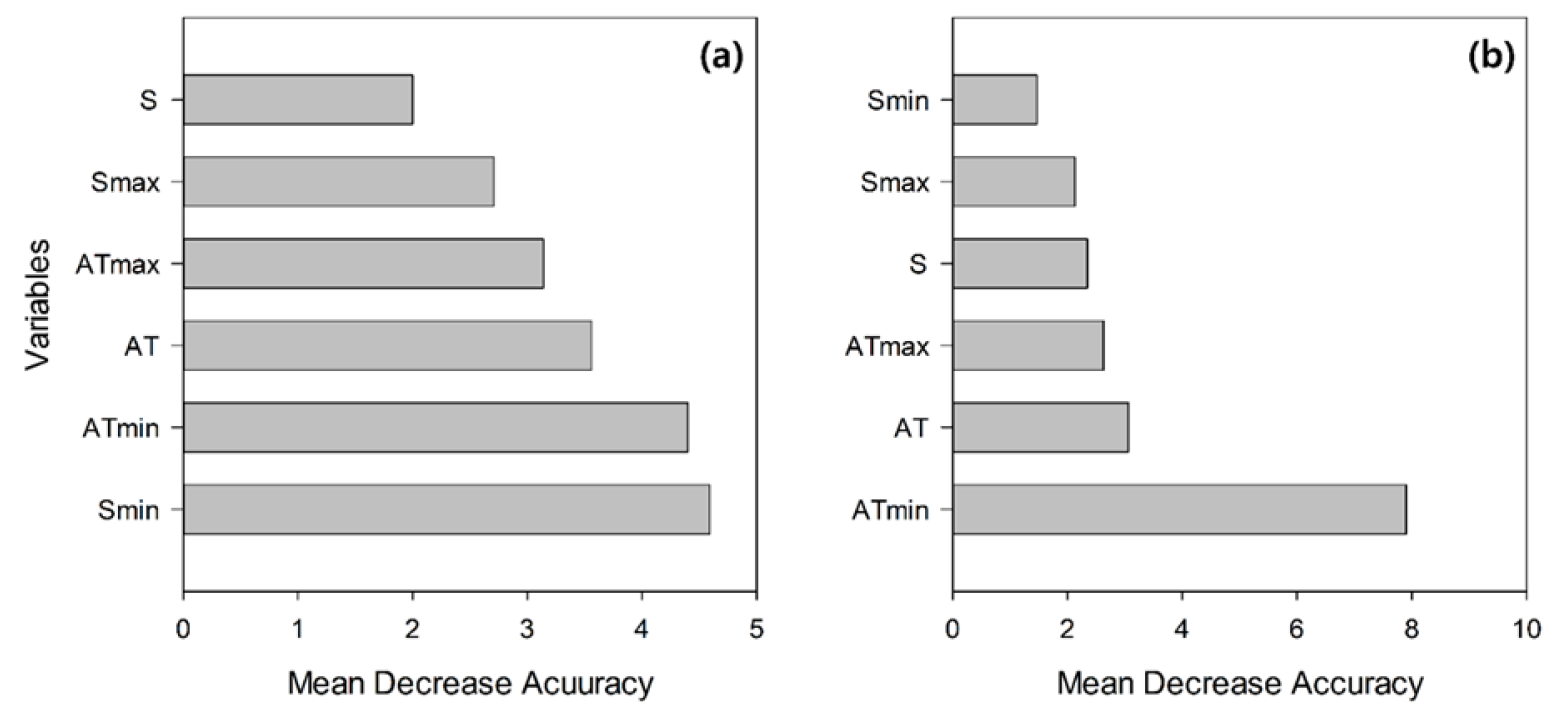

Figure 5. Results of the variable importance calculation based on MDA for the warm season (a) and cold season (b), indicating which variables have a positive effect on the overall accuracy.

Using the completed random forest models, the dominant species among the five barnacles in each sampling site at the experimental periods in the present study were predicted 
(Table 4). Moreover, considering a simple climate change situation (see Materials and Methods), the dominant species after 30, 50, and 100 years were predicted (Table 4). During the warm season, the dominant species predicted during the experimental seasons coincided with the observed dominant species, except for $\mathrm{DH}$. After 100 years, the indigenous species, TRI, was predicted to be the dominant species at JB, YP, and US, where PER and IMP currently dominated, and it was predicted to be the dominant species at most sampling sites in the East Sea. There was no change between the observed dominant species and predicted dominant species over time in the Korea Strait, and IMP was predicted to be the dominant species at all the sampling sites in the Yellow Sea after 30 years and longer. For the cold season, the dominant species predicted during the experimental seasons coincided with the observed dominant species at most of the sampling sites except for SC and MP (Table 4). After 100 years, BTR was predicted to be the dominant species at SC, US, BS, and MP, and PER was predicted to be the dominant species at most sampling sites in the East Sea and the Korea Strait (DH, JB, YP, TY, and KY). BTR and AMP were predicted to be the dominant species in the Yellow Sea (MP, DJ, and IC) after 100 years, which was consistent with the observed dominant species, except for BE.

Table 4. The observed dominant species among five barnacles in each sampling site at the experimental periods in the present study and the dominant species predicted by random forest classification. In addition, dominant species after 30,50 , and 100 years were predicted based on simple climate change conditions (see Materials and Methods).

\begin{tabular}{|c|c|c|c|c|c|c|}
\hline \multicolumn{7}{|c|}{ Warm Season } \\
\hline & Location & $\begin{array}{c}\text { Observed } \\
\text { Dominant Species }\end{array}$ & $\begin{array}{c}\text { Estimated } \\
\text { Dominant Species }\end{array}$ & After 30 Years & After 50 Years & After 100 Years \\
\hline \multirow{5}{*}{ East Sea } & SC & TRI & TRI & TRI & TRI & TRI \\
\hline & $\mathrm{DH}$ & TRI & PER & PER & PER & PER \\
\hline & $\mathrm{JB}$ & PER & PER & PER & PER & TRI \\
\hline & YP & PER & PER & TRI & TRI & TRI \\
\hline & US & IMP & IMP & TRI & TRI & TRI \\
\hline \multirow{4}{*}{ Korea Strait } & BS & TRI & TRI & TRI & TRI & TRI \\
\hline & TY & IMP & IMP & IMP & IMP & IMP \\
\hline & KY & TRI & TRI & TRI & TRI & TRI \\
\hline & YS & TRI & TRI & TRI & TRI & TRI \\
\hline \multirow{4}{*}{ Yellow Sea } & MP & TRI & TRI & IMP & IMP & IMP \\
\hline & $\mathrm{BE}$ & IMP & IMP & IMP & IMP & IMP \\
\hline & DJ & IMP & IMP & IMP & IMP & IMP \\
\hline & IC & AMP & AMP & IMP & IMP & IMP \\
\hline \multicolumn{7}{|c|}{ Cold Season } \\
\hline & Location & $\begin{array}{c}\text { Observed } \\
\text { Dominant Species }\end{array}$ & $\begin{array}{c}\text { Estimated } \\
\text { Dominant Species }\end{array}$ & After 30 Years & After 50 Years & After 100 Years \\
\hline \multirow{5}{*}{ East Sea } & SC & TRI & EBU & PER & PER & TRI \\
\hline & $\mathrm{DH}$ & PER & PER & PER & PER & PER \\
\hline & $\mathrm{JB}$ & PER & PER & PER & TRI & PER \\
\hline & YP & TRI & TRI & TRI & PER & PER \\
\hline & US & PER & PER & PER & TRI & TRI \\
\hline \multirow{4}{*}{ Korea Strait } & BS & TRI & TRI & TRI & TRI & TRI \\
\hline & TY & IMP & IMP & PER & PER & PER \\
\hline & KY & IMP & IMP & IMP & IMP & PER \\
\hline & YS & TRI & TRI & IMP & IMP & IMP \\
\hline \multirow{4}{*}{ Yellow Sea } & $\mathrm{MP}$ & TRI & IMP & IMP & TRI & TRI \\
\hline & $\mathrm{BE}$ & AMP & AMP & AMP & AMP & IMP \\
\hline & DJ & AMP & AMP & AMP & AMP & AMP \\
\hline & IC & AMP & AMP & AMP & AMP & AMP \\
\hline
\end{tabular}




\section{Discussion}

Invasive barnacles are considered one of the drivers of ecological change and can alter the habitat of and displace native species [8]. In Korea, a territory with three sides surrounded by the sea and many ports, the invasion of exotic barnacles has the potential to threaten the survival of indigenous species. In the present study, four invasive barnacles, AMP, EBU, IMP, and PER, and one indigenous barnacle, TRI, were sampled to assess the effects of water temperature and salinity on the barnacles and the possibility that the exotic species may displace the native barnacle.

Among these invasive barnacles, AMP, IMP, and PER have been invading the seas of Korea for more than 20 years, and have settled at high densities in the east sea, Korea Strait, and the Yellow Sea, respectively. Although it has been many years since the invasion of these species, their main habitat tends to be confined to one sea area. This is thought to be because the three sea areas of Korea possess very different oceanographic characteristics [14]. The East Sea is a sea area affected by both the Tsushima Warm Current and North Korean Cold Current [31,32], while the Korea Strait is directly influenced by the Tsushima Warm Current [33]. Alternatively, the Yellow Sea is greatly influenced by the inflow of fresh water from land because this sea is semi-closed with a low depth [14]. For these reasons, the Yellow Sea showed the lowest salinity and the widest variation in annual water temperature among the three sea areas, and the East Sea showed the opposite trends (Figure 2) [14]. Therefore, the different oceanographic characteristics of the three sea areas have resulted in a variety of non-native species settling in the seas of Korea.

Unlike the exotic barnacles, the indigenous species, TRI, was found in the ports in all sea areas except Incheon (IC) and was found at higher density in the warm season than in the cold season (Figure 2). Thus, TRI is able to adapt to all water temperatures and salinity ranges in the three sea areas of Korea and has better fitness in the warm season than in the cold season. According to the literature, AMP, IMP, and PER invaded in 1979, the 1990s, and 2000, respectively (Table 1). Approximately 20 to 40 years after their invasion, out of a total of 13 ports, TRI was dominant in only six and five ports during the warm and cold seasons, respectively. These results indicate that invasive barnacles have already been established and have spread dominantly in some ports. In addition, given the progression of global climate change, species in a region may expand their distribution or increase their abundance [7-9,34]. Therefore, it is necessary to monitor the risks posed by exotic barnacles through long-term sampling and appropriate prediction methods.

Temperature and salinity are important factors that regulate the survival and recruitment of many marine invertebrates [35]. In addition, many researchers have studied the effects of water temperature and salinity on barnacles in the laboratory and field, and these factors have a large impact on larval development and attachment of barnacles [11,12,36]. In the present study, the results of the NMDS analysis showed that the compositions of the five barnacles in the East Sea and the other areas were statistically different, and that six parameters related to water temperature and salinity were significantly correlated with the NMDS space (Table 3). Therefore, in the present study, these six parameters were employed to predict the dominant species in the sampling ports via a random forest model, and the model displayed high accuracy (Table S3). Moreover, the estimate of dominant species demonstrated an accuracy of approximately $92 \%$ when compared with the observed values, indicating that the predictive power of the model is very high (Table 4). This result verifies that the most influential factors in determining the dominant species of barnacles on a regional scale are water temperature and salinity; hence, these parameters should be considered the most important factors for determining whether exotic barnacles dominate in an area.

According to the results of the RF model developed in the present study, in the warm season, IMP is an invasive species that is likely to become the dominant species in the seas of Korea against the backdrop of simple climate change (Table 4). As IMP usually thrives in areas of relatively low salinity [37], it is expected to dominate in the Yellow Sea, where salinity is the lowest and where it is expected to decrease in the future. However, in the 
cold season, AMP has the potential to dominate owing to the low temperatures of the Yellow Sea, wherein the annual water temperature range is the widest. In the Korea Strait and the East Sea, the native species TRI is expected to continue to dominate in the warm seasons even considering climate change. However, in the cold season, PER is expected to be the most dominant species. A previous study showed that PER is concentrated in the East Sea, where some of the international shipping traffic ports are located [13]. As the water temperature in the Korea Strait in the cold season increases owing to climate change, PER, which dominates mainly in winter in the East Sea, is expected to dominate in ports in the Korea Strait. Although the results of the attachment plate analysis could not fully represent the barnacle community under natural conditions because it was only a short-term survey of 6 months per season, the results of the RF model assert the necessity of preparing for damage to indigenous species resulting from the dominance of IMP and AMP in the Yellow Sea, and PER in the Korea Strait and the East Sea.

In the present study, it was concluded that the distribution and abundance of the barnacles could be determined by water temperature and salinity. However, there are various environmental variables that affect the fitness of barnacles other than water temperature and salinity. For example, at the length scale of $60-70 \mathrm{~km}$, spatially structured variables, such as upwelling, wind velocity, and surface slicks, correlate significantly with recruitment rate [38]. Additionally, chemical properties, such as $\mathrm{pH}$ and oxygen content, have been shown to affect the life-history traits of barnacles in laboratory experiments $[39,40]$. Therefore, further studies are needed to investigate how influential environmental variables other than water temperature and salinity affect species composition of barnacle on a regional-scale survey.

\section{Conclusions}

Korea has three sea areas affected by various ocean currents, with a distinct difference between the warm and cold seasons; thus, it is a habitat containing diverse environmental conditions with temporal and spatial variation. Owing to these features, four invasive barnacles from foreign regions and one indigenous barnacle were able to settle and inhabit simultaneously in the seas of Korea [18]. As changes in the environment, such as those caused by climate change, have the potential to increase the distribution and density of invasive species [33], it is necessary to determine which environmental variables have a significant influence on their habitat preferences. In the present study, IMP and AMP in the Yellow Sea and PER in the East Sea and Korea Strait are predicted to be the dominant species in the future. The results of this study show that six parameters related to water temperature and salinity are sufficient to explain the current distribution and abundance of barnacles and predict future trends. In addition, the random forest model is shown to be an adequate method for predicting dominant barnacle. This study proposes that, along with constant monitoring of invasive species and collection of data for environmental variables, identification of the relationship between these two parameters may provide vital knowledge to be used to prepare for environmental changes.

Supplementary Materials: The following are available online at https:/ /www.mdpi.com/2071-105 0/13/2/634/s1, Table S1: Abbreviation, geographical coordination, and sea area of each sampling site, Table S2: The geographical coordination of 28 ports in Korea presenting surface water temperature and salinity information from the marine environment monitoring network of Korea (MOF, 2020), Table S3: OOB error and test accuracy for the ntree (number of trees to grow) and mtry (number of variables used to split each node) combination used in the warm and cold seasons.

Author Contributions: Conceptualization, M.D.U.; Data curation, Y.-S.L.; Formal analysis, Y.-S.L. and J.H.; Investigation, M.D.U. and T.L.; Methodology, M.D.U. and Y.-S.L.; Project administration, S.S.; Supervision, I.H.K. and S.S.; Writing—original draft, Y.-S.L.; Writing—review \& editing, S.S. All authors have read and agreed to the published version of the manuscript. 
Funding: This research was a part of the project titled "Improvement of management strategies on marine disturbing and harmful organisms (No. 20190518)", funded by the Ministry of Oceans and Fisheries, Korea.

Data Availability Statement: The data presented in this study are available on request from the corresponding author.

Conflicts of Interest: The authors declare no conflict of interest.

\section{References}

1. Pasternak, Z.; Achituv, Y. Feeding behavior of shallow-water barnacles from the Mediterranean and Red Sea. J. Crustacean Biol. 2007, 27, 543-547. [CrossRef]

2. Luckens, P.A. Competition and intertidal zonation of barnacles at Leigh, New Zealand. N. Z. J. Mar. Fresh. 1975, 9, 379-394. [CrossRef]

3. Brusca, R. Common Intertidal Invertebrates of the Gulf of California, 2nd ed.; University of Arizona Press: Tucson, AZ, USA, 1980; pp. 1-513.

4. Carlton, J.T.; Newman, W.A.; Pitombo, F.B. Barnacle invasions: Introduced, cryptogenic, and range expanding Cirripedia of North and South America. In the Wrong Place-Alien Marine Crustaceans: Distribution, Biology and Impacts; Springer: Dordrecht, The Netherlands, 2011; pp. 159-213.

5. Sax, D.F.; Gaines, S.D. Species invasions and extinction: The future of native biodiversity in islands. Proc. Natl. Acad. Sci. USA 2008, 105, 11490-11497. [CrossRef] [PubMed]

6. Heard, M.J.; Sax, D.F. Coexistence between native and exotic species is facilitated by asymmetries in competitive ability and susceptibility to herbivores. Ecol. Lett. 2013, 16, 206-213. [CrossRef] [PubMed]

7. Baird, D.; Asmus, H.; Asmus, R. Effect of invasive species on the structure and function of the Sylt-Rømø Bight ecosystem, northern Wadden Sea, over three time periods. Mar. Ecol. Prog. Ser. 2012, 462, 143-162. [CrossRef]

8. Bracewell, S.A.; Spencer, M.; Marrs, R.H.; Iles, M.; Robinson, L.A. Cleft, crevice or the inner thigh: 'Another place' for the establishment of the invasive barnacle Austrominius modestus (Darwin, 1854). PLoS ONE 2012, 7, e48863. [CrossRef]

9. Gallagher, M.C.; Davenport, J.; Gregory, S.; McAllen, R.; O'Riordan, R. The invasive barnacle species, Austrominius modestus: Its status and competition with indigenous barnacles on the Isle of Cumbrae, Scotland. Estuar. Coast. Shelf Sci. 2015, 152, 134-141. [CrossRef]

10. Herbert, R.J.H.; Hawkins, S.J.; Sheader, M.; Southward, A.J. Range extension and reproduction of the barnacle Balanus perforatus in the eastern English Channel. J. Mar. Biol. Assoc. UK 2003, 83, 73-82. [CrossRef]

11. Nasrolahi, A.; Pansch, C.; Lenz, M.; Wahl, M. Being young in a changing world: How temperature and salinity changes interactively modify the performance of larval stages of the barnacle Amphibalanus improvisus. Mar. Biol. 2012, 159, 331-340. [CrossRef]

12. Thiyagarajan, V.; Harder, T.; Qian, P.Y. Combined effects of temperature and salinity on larval development and attachment of the subtidal barnacle Balanus trigonus Darwin. J. Exp. Mar. Biol. Ecol. 2003, 287, 223-236. [CrossRef]

13. Choi, K.H.; Choi, H.W.; Kim, I.H.; Hong, J.S. Predicting the invasion pathway of Balanus perforatus in Korean seawaters. Ocean Polar Res. 2013, 35, 63-68. [CrossRef]

14. Park, C.; Kim, S.T.; Hong, J.S.; Choi, K.H. A rapid assessment survey of invasive species of macrobenthic invertebrates in Korean waters. Ocean Sci. J. 2017, 52, 1-9.

15. Kim, I.H.; Kim, H.S. Systematic studies on the Cirripeds (Crustacea) from Korea: I. Balanomorph barnacles (Cirripedia, Thoracica, Balanomorpha). Korean J. Zool. 1980, 23, 161-194.

16. Kim, I.H. Invasion of foreign barnacles into Korean waters. Korean J. Syst. Zool. 1992, 8, 163-175.

17. Kim, I.H.; Hong, J.S. Introduction of the European common barnacle Balanus perforatus Brugiére (Crustacea, Cirripedia) into Korean waters. In Proceedings of the17th International Conference on Aquatic Invasive Species (ICAIS), San Diego, CA, USA, 29 August-2 September 2010; p. 24.

18. Shin, S.; Park, J.H.; Lee, J.S.; Kim, I.H.; Seo, J.E.; Kim, H.S.; Min, G.S.; Kim, S.H. Marine Introduced Benthos of Korea; Ministry of oceans and fisheries: Seoul, Korea, 2013; p. 102.

19. Kim, I.H. Cirripedia, Symbiotic Copepoda, Pycnogonida. Illustrated Encyclopedia of Fauna and Flora of Korea; Ministry of Education: Seoul, Korea, 1998; Volume 38, pp. 1-1038.

20. Schneider, C.A.; Rasband, W.S.; Eliceiri, K.W. NIH Image to ImageJ: 25 years of image analysis. Nat. Mathods 2012, 9, 671-675. [CrossRef] [PubMed]

21. Harriott, V.J.; Fisk, D.A. A comparison of settlement plate types for experiments on the recruitment of scleractinian corals. Mar. Ecol. Prog. Ser. 1987, 37, 201-208. [CrossRef]

22. Fisk, D.A.; Harriott, V.J. Spatial and temporal variation in coral recruitment on the Great Barrier Reef: Implications for dispersal hypotheses. Mar. Biol. 1990, 107, 485-490. [CrossRef]

23. Guy-Haim, T.; Rilov, G.; Achituv, Y. Different settlement strategies explain intertidal zonation of barnacles in the Eastern Mediterranean. J. Exp. Mar. Biol. Ecol. 2015, 463, 125-134. [CrossRef]

24. Pebesma, E.J. Multivariable geostatistics in S: The gstat package. Comput. Geosci. 2004, 30, 683-691. [CrossRef] 
25. MOF (Ministry of Ocean and Fisheries). Marine Environment Monitoring Network. Available online: https://www.meis.go.kr/ mei/observe/port.do (accessed on 15 October 2020).

26. Breiman, L. Random forests. Mach. Learn. 2001, 45, 5-32. [CrossRef]

27. Hapfelmeier, A.; Ulm, K. A new variable selection approach using Random Forests. Comput. Stat. Data Anal. 2013, 60, 50-69.

28. Rhein, M.; Rintoul, S.R.; Aoki, S.; Campos, E.; Chambers, D.; Feely, R.A.; Gulev, S.; Johnson, G.C.; Josey, S.A.; Kostianoy, A.; et al. Observations: Ocean. In Climate Change 2013: The Physical Science Basis: Contribution of Working Group I to the Fifth Assessment Report of the Intergovernmental Panel on Climate Change; Stocker, T.F., Qin, D., Plattner, G.K., Tignor, M., Allen, S.K., Boschung, J., Nauels, A., Xia, Y., Bex, V., Midgley, P.M., Eds.; Cambridge University Press: Cambridge, UK, 2013; pp. $255-316$.

29. Nakano, T.; Kaneko, I.; Soga, T.; Tsujino, H.; Yasuda, T.; Ishizaki, H.; Kamachi, M. Mid-depth freshening in the North Pacific subtropical gyre observed along the JMA repeat and WOCE hydrographic sections. Geophys. Res. Lett. 2007, 34 , L23608.

30. Liaw, A.; Wiener, M. Classification and regression by randomForest. R News 2002, 2, 18-22.

31. Chang, K.I.; Hogg, N.G.; Suk, M.S.; Byun, S.K.; Kim, Y.G.; Kim, K. Mean flow and variability in the southwestern East Sea. Deep Sea Res. 2002, 49, 2261-2279.

32. Choi, B.J.; Haidvogel, D.B.; Cho, Y.K. Interannual variation of the polar front in the Japan/East Sea from summertime hydrography and sea-level data. J. Mar. Syst. 2009, 78, 351-362.

33. Lee, T. Characteristics of nutrient distribution in summer and winter in the South Sea. Sea 1999, 4, 371-382.

34. Rahel, F.J.; Bierwagen, B.; Taniguchi, Y. Managing aquatic species of conservation concern in the face of climate change and invasive species. Conserv. Biol. 2008, 22, 555-561.

35. Anil, A.C.; Chiba, K.; Okamoto, K.; Kurokura, H. Influence of temperature and salinity on larval development of Balanus amphitrite: Implications in fouling ecology. Mar. Ecol. Prog. Ser. 1995, 118, 159-166.

36. Dineen, J.F.; Hines, A.H. Effects of salinity and adult extract on settlement of the oligohaline barnacle Balanus subalbidus. Mar. Biol. 1994, 119, 423-430.

37. Kim, H.K.; Lee, S.K.; Min, B.S.; Kim, W. Report on the current status of the distribution of invasive barnacles in marine national park areas of Korea. J. Natl. Park Res. 2019, 10, 249-257.

38. Lagos, N.A.; Castilla, J.C.; Broitman, B.R. Spatial environmental correlates of intertidal recruitment: A test using barnacles in northern Chile. Ecol. Monogr. 2008, 78, 245-261. [CrossRef]

39. Campanati, C.; Yip, S.; Lane, A.; Thiyagarajan, V. Combined effects of low $\mathrm{pH}$ and low oxygen on the early-life stages of the barnacle Balanus amphitrite. ICES J. Mar. Sci. 2016, 73, 791-802. [CrossRef]

40. Resner, E.J.; Belanger, B.G.; Clayton, L.C.; Marsh, K.G.; Hardy, K.M. Physiological response of the giant acorn barnacle, Balanus nubilus, to oxygen-limiting environments. J. Exp. Mar. Biol. Ecol. 2020, 532, 151447. [CrossRef] 